\title{
Isolasi dan Identifikasi Senyawa Metabolit Sekunder Fraksi Metanol Batang Belajang Susu (Scindapsus pictus Hassk.)
}

\section{Isolation and Identification of Secondary Metabolite Methanol fraction of Belajang Susu (Scindapsus pictus Hassk) stem extract}

\author{
${ }^{1)}$ Nurul Amaliah, ${ }^{2}$ Pince Salempa, ${ }^{3)}$ Muharram \\ ${ }^{123)}$ Jurusan Kimia Fakultas Matematika dan Ilmu Pengetahuan Alam \\ Universitas Negeri Makassar, Jl. Dg Tata Raya Makassar, Makassar 90224 \\ Email:nurulamaliahn27@yahoo.com
}

\begin{abstract}
ABSTRAK
Penelitian ini adalah penelitian eksplorasi yang bertujuan untuk mengisolasi senyawa metabolit sekunder dalam fraksi metanol batang belajang susu (S. pictus Hassk). Sampel penelitian diambil dari kecamatan Mambi, kabupaten Mamasa, Sulawesi Barat. Penelitian dilakukan melalui beberapa tahap yaitu ekstraksi (maserasi), fraksinasi, pemurnian, dan identifikasi. Isolat murni yang diperoleh dengan cara rekristalisasi berupa kristal berwarna putih berbentuk serbuk dengan titik leleh $250-252^{\circ} \mathrm{C}$. Identifikasi dengan spektrofotometer inframerah memberikan serapan yang khas untuk gugus fungsi $\mathrm{OH}, \mathrm{CH}_{2}$ dan $\mathrm{CH}_{3}$ gem dimetil, C-O, serta $=\mathrm{C}-\mathrm{H}$. Berdasarkan hasil uji golongan dan data spektrum FTIR maka disimpulkan bahwa senyawa yang diperoleh adalah senyawa golongan triterpenoid.
\end{abstract}

Kata kunci: Belajang Susu, S. pictus Hassk dan Triterpenoid

\begin{abstract}
This research is an exploratory research that aimed to isolating compounds of secondary metabolite methanol fraction of Belajang Susu (Scindapsus pictus Hassk) stem extract. The sample of this research is taken from Mambi sub-district, Mamasa district, West Sulawesi. The research was done through several stages: extraction (maceration), fractionation, purification and identification. The pure isolates obtained by recrystallization in form of the white crystals, powder crystals with melting point $250-252^{\circ} \mathrm{C}$. Identification with an infrared spectrophotometer giving wave number of functional groups $\mathrm{OH}, \mathrm{CH}_{2}$ and $\mathrm{CH}_{3}$ gem dimetyl, $\mathrm{C}-\mathrm{O}$, and $=\mathrm{C}-\mathrm{H}$. Based on the results of the group test and FTIR spectrum data it was concluded that the compounds obtained were triterpenoid group compounds.
\end{abstract}

Keywords: Belajang Susu, S. pictus Hassk, and Triterpenoid 


\section{PENDAHULUAN}

Indonesia termasuk salah satu negara yang kaya keanekaragaman hayati. Di dunia terdapat kurang lebih 250.000 jenis tumbuhan tinggi, dan lebih $60 \%$ dari jumlah ini merupakan tumbuhan tropika (Atun, 2014). Diketahui sebanyak 20.000 jenis tumbuhan obat terdapat di Indonesia, namun baru sebanyak 1.000 jenis tumbuhan yang terdata dan hanya 300 yang dimanfaatkan sebagai obat tradisional (Wijaya, 2014).

Tumbuhan obat tersebut menghasilkan senyawa metabolit sekunder yang berpotensi sebagai senyawa bioaktif dan berguna bagi kehidupan manusia. Setiap tumbuhan menghasilkan satu atau lebih senyawa bioaktif dalam bentuk metabolit sekunder, seperti alkaloid, flavonoid, fenilpropanoid, steroid, terpenoid, tanin, dan kumarin yang keberadaannya sangat tergantung pada jenis tumbuhan. Hal inilah yang menyebabkan tumbuhan dapat digunakan sebagai obat-obatan sejak ratusan bahkan ribuan tahun yang lalu.

Salah satu famili tumbuhan yang dimanfaatkan sebagai tanaman obat adalah Araceae. Spesies yang termasuk dalam famili ini kaya akan kandungan antosianin yang ada di perbungaan, buah, daun atau tangkai daun (Kaur, 2016). Beberapa spesies yang dapat dimanfaatkan sebagai tanaman obat seperti Alocasia macrorrhiza Schott digunakan sebagai obat batuk, Acorus calamus L digunakan sebagai obat penenang dan Pistia Stratiotes L digunakan sebagai obat batuk rejan, demam dan untuk pelancar air seni (Hutapea, 2000).
Tumbuhan belajang susu ( $S$. pictus Hassk.) adalah salah satu spesies yang termasuk dalam famili Araceae dan marga Scindapsus. Umumnya anggota marga ini digunakan sebagai tanaman hias. Namun, ada juga yang dimanfaatkan sebagai tanaman obat (Yuzammi, 2015). Seperti Scindapsus officinalis yang ekstrak metanolnya mengandung senyawa aktif yang bersifat antiinflamasi, analgesik, antioksidan dan antitumor (Kaur, 2016).

Berdasarkan hasil riset khusus eksplorasi tumbuhan lokal di Indonesia berbasis komunitas etnis Mambi dari Kecamatan Mambi, Kabupaten Mamasa, Sulawesi Barat yaitu tumbuhan belajang susu $(\underline{S}$. pictus Hassk.) dimanfaatkan sebagai antikanker (Jumadi, 2012). Selain itu, tumbuhan ini dilaporkan mengandung oksalat yang biasanya dalam bentuk kalsium oksalat, flavonoid sulfat dan campuran flavon dan flavonol sulfat (Kaur, 2016).

Berdasarkan pendekatan kemotaksonomi dan etnobotani menunjukkan adanya potensi ditemukan senyawa metabolit sekunder pada tumbuhan belajang susu (S. pictus Hassk.). Pendekatan kemotaksonomi yaitu pemilihan tumbuhan berdasarkan pada kedekatan kekerabatan tumbuhan yang telah diketahui memiliki kandungan kimia tertentu. Tumbuhan atau organisme lain dalam satu famili sering dijumpai memproduksi senyawa yang mirip secara alami. Sedangkan pendekatan etnobotani yaitu eksplorasi awal bahan aktif suatu tumbuhan berdasarkan pengetahuan dan kebiasaan 
masyarakat tradisional dalam pengobatan penyakit tertentu (Mamahit, 2009). Oleh karena itu, peneliti menganggap perlu diadakan suatu penelitian untuk mengkaji lebih dalam kandungan senyawa metabolit sekunder dari ekstrak metanol batang belajang susu (S. pictus Hassk.).

\section{METODE PENELITIAN}

\section{A. Alat dan Bahan}

Alat yang digunakan dalam penelitian ini diantaranya wadah maserasi, corong Buchner, chamber KLT, pipa kapiler, alat untuk fraksinasi meliputi kromatografi kolom cair vakum (KKCV) dan kromatografi kolom tekan (KKT). Kemudian beberapa peralatan seperti neraca analitik, evaporator, alat pengukur titik leleh dan spektrofotometer Shimadzu type Prestige-21FT-IR.

Bahan yang digunakan adalah serbuk halus batang belajang susu, metanol, $n$-heksana, etil asetat, kloroform dan aseton. Beberapa reagen seperti pereaksi LiebermannBuchard untuk uji kualitatif steroid, Wagner dan Dragendorff untuk uji kualitatif alkaloid, besi (III) klorida $1 \%$ untuk uji kualitatif flavonoid, serium sulfat $\left(\mathrm{CeSO}_{4}\right)$ sebagai penampak noda. Bahan-bahan lain yang digunakan yaitu pelat KLT, kertas saring Whatman nomor 41, silica gel $60 \mathrm{GF}_{254}$ (untuk kolom vakum), silica gel $60(0,2-0,5 \mathrm{~mm})$ untuk imprek sampel dan silika gel 60 (0,063-0,200 mm) untuk KKT.

\section{B. Prosedur Kerja 1. Persiapan Bahan}

Batang belajang susu dibersihkan lalu dipotong kecil-kecil kemudian dikeringkan dengan cara diangin-anginkan pada suhu kamar hinga kering. Setelah itu digiling hingga diperoleh 4,23 $\mathrm{kg}$ serbuk batang belajang susu.

\section{Ekstraksi}

Sebanyak 4,23 kg serbuk halus batang belajang susu dimaserasi dengan metanol selama 3 x 24 jam. Kemudian maserat disaring dengan corong Buchner lalu dipekatkan menggunakan evaporator sampai kirakira tinggal seperempat dari volume awal. Selanjutnya dilakukan uji pendahuluan (uji golongan) terhadap ekstrak metanol yang diperoleh dengan berbagai pereaksi diantaranya pereaksi Liebermann-Burchard (steroid), $\mathrm{FeCl}_{3} \quad 1 \%$ (flavonoid), Dragendorff (alkaloid) dan Wagner (alkaloid).

\section{Fraksinasi}

Ekstrak metanol yang diperoleh terlebih dahulu diidentifikasi menggunakan kromatografi lapis tipis (KLT). Sejumlah kecil ekstrak ditotolkan pada pelat KLT dengan menggunakan berbagai macam eluen pada berbagai perbandingan untuk mengetahui jenis pelarut dan perbandingan yang sesuai pada kromatografi kolom cair vakum. Kemudian dideteksi di bawah lampu UV dan dilanjutkan dengan penyemprotan larutan serium sulfat lalu dipanaskan. 
Berdasarkan hasil KLT diperoleh bahwa eluen $n$-heksana:etil asetat (8:2) memberikan pola pemisahan yang baik dan jelas untuk kromatografi kolom cair vakum.

Proses fraksinasi pertama dilakukan dengan metode kromatografi kolom cair vakum, sebanyak 55,54 g ekstrak metanol batang belajang susu yang berbentuk pasta terlebih dahulu di impregnasi dengan silika gel $60(0,2-0,5 \mathrm{~mm})$ hingga tercampur merata dan berbentuk pasir. Kemudian kedalam kolom ditempatkan secara berturutturut dari bagian bawah hingga atas yaitu silika gel $60 \mathrm{GF}_{254}$ pada bagian paling bawah (fase diam) dan dirapatkan hingga padat, kertas saring whatman, sampel yang telah di impregnasi. Kolom yang telah terkemas kemudian di elusi dengan larutan yang sesuai sebagai fase geraknya. Pengelusian dimulai dari pelarut yang bersifat nonpolar yaitu $n$ heksan $100 \%$ kemudian ditingkatkan kepolarnnya dengan menambahkan campuran pelarut $\mathrm{n}$-Heksan:etil asetat mulai dari perbandingan 95:5 dan ditingkatkan secara bergradien hingga etil asetat 100\% kemudian dengan eluen etil asetat-aseton pada perbandingan (95:5) hingga eluen aseton $100 \%$ dan terakhir dengan pelarut polar yaitu metanol $100 \%$. Fraksi yang diperoleh sebanyak 30 fraksi diidentifikasi menggunakan KLT dengan eluen yang sesuai. Fraksi-fraksi yang mempunyai profil noda yang sama digabung sehingga di peroleh 9 fraksi utama. Hasil KKCV yang diperoleh diuapkan pada suhu ruang.
Fraksi $\mathrm{G}$ dengan berat 1,64 gr dipilih untuk difraksinasi dengan metode kromatografi kolom tekan. Sebelum difraksinasi terlebih dahulu diidentifikasi dengan KLT untuk menentukan eluen yang akan digunakan pada KKT. Kolom untuk fraksinasi dengan KKT diisi dengan silika gel $60(0,063-0,200 \mathrm{~mm})$ hingga tinggi $\pm 15 \mathrm{~cm}$ sebagai fase diam kemudian diisi sampel yang telah diimpregnasi dan eluen yang sesuai sebagai fasa gerak. Fraksi-fraksi yang diperoleh sebanyak 13 fraksi dianalisis menggunakan KLT dengan eluen yang sesuai. Fraksi-fraksi yang mempunyai profil noda yang sama digabung dan di peroleh 6 faksi utama kemudian diuapkan pada suhu ruang.

Isolat $\mathrm{G}_{6}$ yang diperoleh dari fraksi gabungan KKT dimurnikan dengan pelarut yang sesuai. Kemurnian senyawa yang diperoleh ditentukan dengan melakukan KLT tiga sistem eluen. Jika hasil KLT memperlihatkan pola noda tunggal, maka senyawa tersebut relatif murni secara KLT. Kemudian dilakukan uji titik leleh, senyawa tersebut dianggap murni apabila titik leleh senyawa menunjukkan trayek titik leleh yang tajam.

\section{Identifikasi}

Isolat diuji menggunakan pereaksi Liebermann-Burchard, $\mathrm{FeCl}_{3}$, Wagner dan Dragendroff untuk mengetahui golongan senyawa metabolit sekunder yang diperoleh dan identifikasi lebih lanjut menggunakan spektrofotometer FTIR Prestige-21 SHIMADZU untuk mengetahui gugus 
Isolasi dan Identifikasi Senyawa Metabolit Sekunder Fraksi Metanol Batang Belajang Susu (Scindapsus pictus Hassk.)

fungsi yang terdapat dalam senyawa tersebut.

\section{HASIL DAN PEMBAHASAN}

Ekstrak kental yang diperoleh pada proses ekstraksi diuji golongan terlebih dahulu. Uji golongan pada ekstrak kental bertujuan untuk mendapat informasi awal metabolit sekunder yang terdapat pada batang belajang susu. Berdasarkan hasil uji golongan diketahui bahwa pada batang belajang susu mengandung metabolit sekunder Triterpenoid dimana uji pereaksi Lieberman-Burchard positif terhadap sampel dengan terbentuknya warna merah keunguan, dan mengandung alkaloid dimana uji pereaksi Wagner membentuk endapan coklat serta uji pereaksi Dragendroff membentuk endapan coklat kemerahan.

Metode fraksinasi didasarkan pada sifat kepolaran eluen yang digunakan sebagai fase gerak dan akan menarik senyawa dengan sifat kepolaran yang sama dan akan melalui silika yang berfungsi sebagai fase diam sehingga senyawa-senyawa tersebut akan terpisah-pisah dalam beberapa fraksi. Metode KKCV merupakan metode awal untuk memisahkan sampel dalam jumlah banyak dan dilanjutkan dengan metade KKT.

Pada dasarnya pemisahan metode KKCV dan KKT memiliki prinsip yang sama perbedaannya hanya terdapat pada ukuran kolom dan jumlah sampel yang dipisahkan. Selain itu, pada metode KKCV sampel dikemas secara kering dan vakum sedangkan KKT dikemas basah dan menggunakan tekanan untuk mempercepat laju eluen. Pengelusian dilakukan secara bergradien mulai dari pelarut non-polar sampai pelarut polar. Hal ini dimaksudkan agar semua senyawa non-polar maupun polar dapat terfraksinasi.

Fraksinasi dilakukan dengan menggunakan silika gel yang memiliki ukuran partikel halus sehingga memiliki kerapatan yang tinggi di dalam kolom. Fraksi yang dipilih untuk fraksinasi lebih lanjut (KKT) dengan pertimbangan adanya target yang ingin dicapai berdasarkan noda yang tampak pada saat KLT tidak banyak dan pemisahannya jelas, selain itu penampakan cirri fisik kristal.

Pemurnian isolat tersebut dilakukan dengan cara rekristalisasi yaitu proses pengkristalan kembali serbuk yang diperoleh.

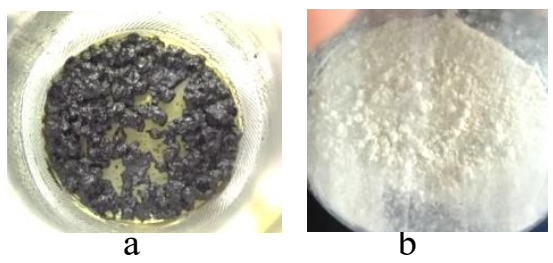

Gambar 1. Hasil KKT (fraksi $\mathrm{C}_{3}$ )

a. Isolat sebelum dimurnikan

b. Isolat murni

Isolat yang diperoleh berbentuk serbuk dengan bobot $71,4 \mathrm{mg}$ pada fraksi $\mathrm{G}_{6}$ diuji kemurniannya dengan metode KLT sistem tiga eluen dengan pelarut dan perbandingan yang berbeda. Hal ini dilakukan untuk memastikan kemurnian dari suatu isolat yang ditunjukkan dengan munculnya satu noda pada tiap KLT. Pemisahan dianggap cukup apabila sudah diperoleh fraksi yang 
menunjukkan noda tunggal pada beberapa uji KLT dengan menggunakan berbagai variasi eluen yang berbeda. Adanya noda tunggal pada beberapa uji KLT tersebut menunjukkan bahwa sudah diperoleh senyawa dengan tingkat kemurnian tinggi (Atun, 2014).
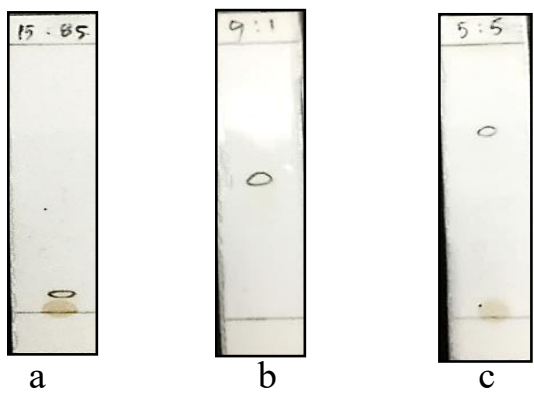

Gambar 2. Kromatogram KLT Tiga Sistem Eluen

a. Eluen aseton : n-heksana $15: 85$

b. Eluen n-heksan : etil asetat $90: 10$

c. Eluen: aseton : etil asetat $50: 50$

Isolat kemudian diuji titik leleh dan hasil yang diperoleh yaitu isolat mulai meleleh pada suhu $250^{\circ} \mathrm{C}$ dan meleleh secara keseluruhan pada suhu 252C. Hal ini menunjukkan bahwa isolat yang diperoleh telah murni karena suatu senyawa murni memiliki trayek titik leleh tajam yakni awal dari melelehnya hingga meleleh secara keseluruhan berada dalam trayek titik leleh tidak lebih dari $2^{\circ} \mathrm{C}$ (Mutiah, 2001).

Isolat murni yang diperoleh diidentifikasi dengan uji golongan dan menggunakan spekstrofotometer IR. Berdasarkan hasil uji golongan diketahui bahwa isolat mengandung metabolit sekunder steroid dimana uji pereaksi Lieberman-Burchard positif terhadap sampel dengan terbentuknya warna merah keunguan.

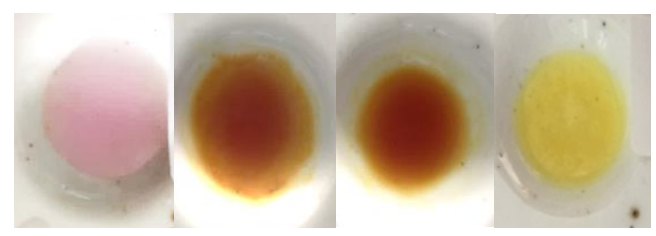

Gambar 3. Hasil Uji Golongan Isolat Murni

a. Lieberman-Burchard

b. Wagner

c. Dragendorff

d. $\mathrm{FeCl}_{3}$

Adapun berdasarkan analisis spektrum infra merah dari isolat fraksi $\mathrm{G}_{6}$ kemungkinan terdapat beberapa gugus fungsi.

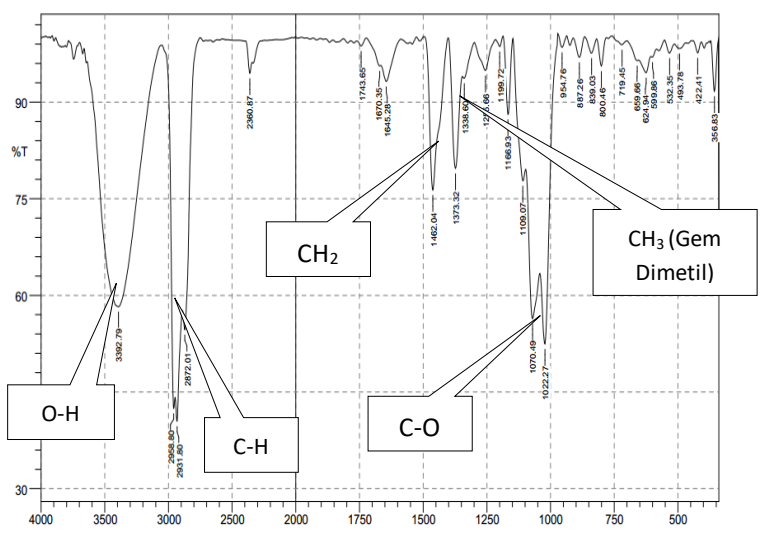

Gambar 4. Spektrum Infra Merah Isolat $\mathrm{G}_{6}$

Pada daerah bilangan gelombang (v) $3392,79 \mathrm{~cm}^{-1}$ yang ditandai dengan pita agak lebar dengan intensitas sedang diidentifikasi sebagai vibrasi ulur O-H. Kemudian adanya serapan tajam dengan intensitas sedang pada daerah bilangan gelombang 1070,49 $\mathrm{cm}^{-1}$ diidentifikasi sebagai vibrasi tekuk C-O. 
Serapan tajam dengan intensitas kuat tampak pada daerah $2958,80 \mathrm{~cm}^{-}$ 1; 2931,80 $\mathrm{cm}^{-1}$ dan $2871,01 \mathrm{~cm}^{-1}$ yang merupakan vibrasi ulur $\mathrm{C}-\mathrm{H}$ alifatik gugus $-\mathrm{CH}_{2}$ dan $-\mathrm{CH}_{3}$. Sifat khas $\mathrm{C}-\mathrm{H}$ alifatik ini ditandai dengan adanya serapan pada daerah 2800-3000. Hal ini menandakan bahwa struktur senyawa isolat mengandung gugus metil dan metilen. Keberadaan gugus metil dan metilena diperkuat dengan adanya vibrasi tekuk $\mathrm{C}-\mathrm{H}$ alifatik pada daerah 1462,04 $\mathrm{cm}^{-1}$ untuk gugus $\mathrm{CH}_{2}$ dan $1373,32 \mathrm{~cm}^{-1}$ untuk gugus $\mathrm{CH}_{3}$ yang mengindikasikan adanya gugus geminal dimetil $-\mathrm{CH}\left(\mathrm{CH}_{3}\right)_{2}$ sebagai ciri khas senyawa triterpenoid. Serapan oleh geminal dimetil biasanya pecah menjadi dua puncak dengan intensitas yang sama, tapi kedua puncak ini tidak selalu tampak pada semua spektra, yang umum dijumpai hanya satu puncak saja (Sastrohamidjojo, H. 1992).

\section{KESIMPULAN DAN SARAN}

\section{A. Kesimpulan}

Berdasarkan hasil penelitian yang diperoleh dapat disimpulkan bahwa seyawa metabolit sekunder yang telah diisolasi dari fraksi metanol tumbuhan $S$. pictus Hassk berupa isolat murni berbentuk serbuk dengan titik leleh $250-252^{\circ} \mathrm{C}$. merupakan senyawa Golongan Triterpenoid.

\section{B. Saran}

Adapun hal-hal yang disarankan berkaitan dengan penyempurnaan penelitian ini adalah sebagai berikut:

1. Perlu dilakukan identifikasi dengan menggunakan spektrometer NMR-
${ }^{1} \mathrm{H}$, NMR $-{ }^{13} \mathrm{C}$ untuk memantapkan struktur senyawa isolat.

2. Perlu dilakukan penelitian lebih lanjut untuk mengetahui senyawasenyawa aktif dalam tumbuhan tersebut untuk dijadikan sebagai bahan baku dalam pembuatan obat.

\section{DAFTAR PUSTAKA}

Atun, S. 2014. Metode Isolasi dan Identifikasi Struktur Senyawa Organik Bahan Alam. Jurnal Konservasi Cagar Budaya Borobudur. Vol. 8. No. 2.

Hutapea, J. R. 2000. Inventaris Tanaman Obat Indonesia (I). Jakarta: Badan Penelitian dan Pengembangan Kesehatan, Departemen Kesehatan RI.

Jumadi, O., Pince S., Ramly dan Raoda. 2012. Riset Khusus Eksplorasi Pengetahuan Lokal Etnomodisin \& Tumbuhan Obat di Indonesia Berbasis Komunitas. Kerjasama Antara Badan Penelitian \& Pengembangan Kesehatan Kementrian Kesehatan RI dengan Lembaga Penelitian Universitas Negeri Makassar.

Kaur, Kuljeet dan Rajiv, G. 2016. Ethnobotanical and phytopharmacological review of Scindapsus officinalis ("Gajapippali"). Asian Pacific Journal of Tropical Biomedicine.

Mamahit, L. 2009. Eikodekana dari Daun Tumbuhan Gedi (Abelmoschus manihot L. Medik) Asal Sulawesi Utara. Chemistry. Prog. Vol. 2. No. 2.

Sastrohamidjojo, H. 1992. Spektroskopi Inframerah. Yogyakarta: Liberty Yogyakarta. 
Isolasi dan Identifikasi Senyawa Metabolit Sekunder Fraksi Metanol Batang Belajang Susu (Scindapsus pictus Hassk.)

Wijaya, B. A., Gayatri, C dan Frenly, W. 2014. Potensi Ekstrak Etanol Tangkai Daun Talas (Colocasia esculenta [L]) Sebagai Alternatif Obat Luka pada Kulit Kelinci (Oryctolagus cuniculus). Pharmacon. Vol. 3. No. 3.
Yuzammi dan Reza, R. R. 2015. Scindapsus splendidus Alderw.: 'Living Type' yang Tersisa Koleksi Kebun Raya Bogor. Warta Kebun Raya. Vol. 13. No. 2. 